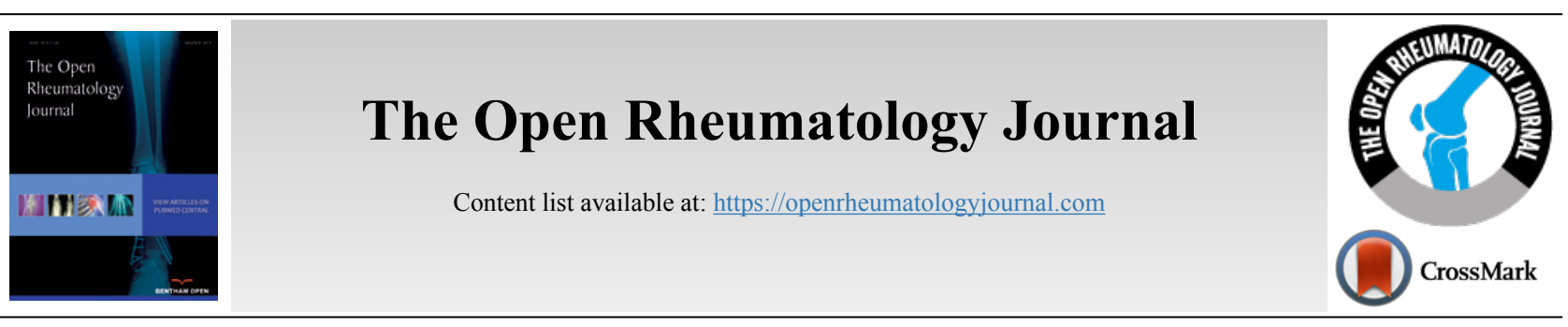

RESEARCH ARTICLE

\title{
Comparative Efficacy of Adalimumab and Etanercept in Children with Juvenile Idiopathic Arthritis Under 4 Years of Age Depending on Active Uveitis
}

Ekaterina Alexeeva $^{1,2,{ }^{*}}$, Tatyana Dvoryakovskaya ${ }^{1,2}$, Rina Denisova ${ }^{1}$, Tatyana Sleptsova ${ }^{1}$, Kseniya Isaeva ${ }^{1}$, Alexandra Chomahidze $^{1}$, Anna Fetisova ${ }^{1}$, Anna Mamutova ${ }^{1}$, Alina Alshevskaya ${ }^{3}$ and Andrey Moskalev ${ }^{3}$

${ }^{\prime}$ Federal State Autonomous Institution "National Medical Research Center of Children's Health" of the Ministry of Health of the Russian Federation, 119991 Lomonosovsky pr., 2, bldg.1, Moscow, Russia

${ }^{2}$ Federal State Autonomous Educational Institution of Higher Education “I.M. Sechenov First Moscow State Medical University”, Ministry of Health of the Russian Federation, Moscow, Russia

${ }^{3}$ Biostatistics and Clinical Trials Center, Novosibirsk, Russia

\section{Abstract:}

Introduction:

In 2011, Etanercept (ETA) was approved for clinical application in patients with Juvenile Idiopathic Arthritis (JIA) older than 2 years of age; Adalimumab (ADA) was approved in 2013. However, the available data for these patients are not sufficient even in large-scale registers. In older children, uveitis is a factor taken into consideration when choosing anti-TNF therapy, so we believe that its onset at an early age may affect the efficacy of treatment with different anti-TNF drugs.

Objectives:

This study aimed to evaluate the comparative efficacy of ADA and ETA in children of young age depending on their uveitis status.

Methods:

Comparative analysis involved patients who had initiated ETA ( $\mathrm{n}=49$, no active uveitis) or ADA ( $\mathrm{n}=25$; 13 patients with active uveitis and 12 patients without uveitis) therapy at an age of $\leq 4$ years. Treatment efficacy was evaluated according to the dynamics of clinical signs and laboratory values, the ACRPedi and Wallace criteria.

Results:

ETA and ADA proved very efficacious in children under 4 years of age already after the first month of therapy according to the disease activity scores, laboratory values, and morning stiffness duration. After 3 months of therapy, the number of affected joints was substantially reduced in all three groups $(\mathrm{p}<0.01)$. The percentage of patients who had achieved ACR50/70/90 by the end of the follow-up period was $42 / 41 / 38$ $(85.7 / 83.7 / 77.6 \%)$ in ETA group, 10/10/9 (76.9/76.9/69.2\%) in ADA group with uveitis, and 9/7/5 (75/58.3/41.7) in ADA group without uveitis, respectively. A comparable proportion of ETA patients and ADA patients with uveitis achieved remission (26 (53.1\%) and 7 (53.8\%), respectively), while only $3(25 \%)$ of ADA patients without uveitis achieved long-term clinical remission ( $p$-values are insignificant).

Conclusion:

In children younger than 4 years, ADA shows higher efficacy in patients with uveitis as compared to those without uveitis. Children without uveitis show a better response to ETA, although there is a risk of de novo uveitis. Therefore, ADA is the drug of choice for children with uveitis under 4 years of age, while ETA is preferred in children without uveitis.

Keywords: Adalimumab, Etanercept, Juvenile idiopathic arthritis, Uveitis, Biologics, CRP.

\begin{tabular}{l|l|l|l}
\hline Article History & Received: October 19, 2018 & Revised: December 7, 2018 & Accepted: December 28, 2018
\end{tabular}

\section{INTRODUCTION}

Juvenile Idiopathic Arthritis (JIA) is a common rheumatic disease of childhood leading to disability if patients do not receive appropriate personalized treatment, which would take into account patient's individual characteristics. Drugs inhibiting the activity of proinflammatory cytokine TNF $\alpha$, such as etanercept and adalimumab, are among the alternatives of 
biologic therapy. Their efficacy has been supported by largescale cohort studies [1 - 3] and several comparative studies. The data obtained for large cohorts of older patients demonstrate that there are some differences in trends for prescription of ETA and ADA [4].

Etanercept (ETA) and Adalimumab (ADA) were approved for clinical use in patients with Juvenile Idiopathic Arthritis (JIA) older than 2 years in 2011 and 2013, respectively [5]. However, the data for these patients are insufficient even in large-scale registers [5 - 8]. This fact makes it impossible to fully solve the problems related to the choice of the optimal anti-TNF drug in young children depending on patient's individual characteristics. The small sample size and the selection bias depending on rheumatologist's personal experience and a specific clinical study impede head-to-head comparison of the efficacies of different anti-TNF drugs, including evaluation of the effect of certain predictors on treatment efficacy. Nevertheless, evaluation of the effect of certain factors on efficacy of treatment with various biologic agents allows one to approach the development of strategies to select the most suitable anti-TNF drug depending on patient's age and past medical history, as well as disease activity. Since uveitis in children of older age groups is one of the factors taken into account when choosing an antiTNF agent, we assumed that its development at an early age might affect the efficacy of treatment with different anti-TNF drugs.

Therefore, the aim of this study was to analyze the comparative efficacy of ETA and ADA in young children depending on whether they had active uveitis or not.

\section{PATIENTS AND METHODS}

This analysis was conducted using the data from the Register of the Federal State Autonomous Institution "National Scientific and Practical Center of Children's Health", the Ministry of Health of the Russian Federation (Moscow, Russia), including the results of two prospective observational studies in patients with JIA treated with anti-TNF drugs. We followed the methods described by Alexeeva et al. 2017 [9], which present results of a full cohort of children treated with ETA at our center. This study involved all children who started to receive ADA or ETA therapy at an age of $\leq 4$ years. The drug was chosen by the physician; ADA was preferred for children with uveitis or aggressive course of arthritis.

All the patients had a verified diagnosis of JIA according to the ILAR criteria. None of the patients had systemic symptoms or signs of tuberculosis. Patients who had started ADA or ETA therapy at an age of $\leq 4$ years were selected for comparative analysis. Etanercept was injected subcutaneously twice a week ( $0.4 \mathrm{mg}$ per $\mathrm{kg}$ body weight; maximum single dose, $25 \mathrm{mg}$ ). Adalimumab was injected subcutaneously in the abdomen at a dose of $24 \mathrm{mg} / \mathrm{m}^{2}$ every 2 weeks.

The study was performed in compliance with the Good Cl-

\footnotetext{
* Address correspondence to this author at the Federal State Autonomous Institution "National Medical Research Center of Children's Health" of the Ministry of Health of the Russian Federation, 119991 Lomonosovsky pr., 2, bldg.1, Moscow, Russia; Tel: +79130079321;

E-mail: ekaterina.i.alekseeva@mail.ru
}

inical Practice (GCP) guidelines. The GCP guidelines ensure reliable study design, study conduct, and communication of data. Patients' rights are protected and subjects' integrity is maintained by the confidentiality of their data. Approval of the study was obtained from the Local Ethics Committee of the Scientific Center of Children's Health (Protocol no. 36 dated October 16, 2008 for ETA and Protocol no. 13 dated March 20, 2009 for ADA). All patients and their parents provided written informed consent for their data to be used in analyses and reported in accordance with the Declaration of Helsinki.

\subsection{Data Collection}

Detailed medical history, including parameters such as age at disease onset, history of at least one uveitis flare, age at uveitis onset, disease duration before study initiation, history of prior medications and concomitant therapy, was collected for each patient at admission. The clinical and laboratory values for each patient were collected after one month, every 3 months during the first year of therapy, and subsequently every 6 months, including global assessment of well-being using the Visual Analogue Scale (0-100 mm Visual Analogue Scale) by patient or parent (patVAS) and by physician (phyVAS), the numbers of active joints, swollen joints, painful joints, and joints with the limited range of motion, the level of C-Reactive Protein (CRP), the Erythrocyte Sedimentation Rate (ESR), and duration of morning stiffness (shown as minutes). The current uveitis activity and its dynamics were assessed by ophthalmologist.

The disease activity indices for juvenile arthritis were calculated: the JADAS71 score [10] and the Childhood Health Assessment Questionnaire score (CHAQ; range 0-3, with 0 being the best score) [11] were determined at each follow-up point.

The investigators documented all the AEs according to the Common Terminology Criteria for Adverse Events: the adverse event onset date and time, narrative, time course, intensity, duration, outcome, causal relationship between the $\mathrm{AE}$ and the study drug, and the alternative etiology for adverse events that are not classified as 'probably related' to etanercept.

The ACR Pedi criteria were used to evaluate the response to therapy [12]. The ACR Pedi 30, 50, 70, and 90 response is defined as at least $30,50,70$, or $90 \%$ improvement, respectively, as compared to the baseline in at least 3 variables of the JIA core set, with no more than one worsening of the variable by $>30 \%$. Clinical remission was defined using the modified Wallace criteria [13]: no active arthritis, no uveitis, no systemic manifestations, normal ESR $(<20 \mathrm{~mm} / \mathrm{h})$, duration of morning stiffness $\leq 15$ minutes, and the physician's global assessment of disease activity score indicating no disease activity $(0-10 \mathrm{~cm})$.

\subsection{Statistical Analysis}

The calculations were performed using the R Statistical Package (http://www.r-project.org). Descriptive statistics were reported as absolute frequencies or medians with the interquartile range. The Mann-Whitney U-test, or Pearson's $\chi^{2}$ test, or Fisher's exact test and non-parametric Kruskal-Wallis test by rank and median multiple comparisons were used 
Table 1. Demographic characteristics of patients under 4 years of age who received ETA and ADA.

\begin{tabular}{|c|c|c|c|c|c|c|}
\hline Parameter & $\begin{array}{l}\text { ADA (no Uveitis) } \\
\qquad(\mathrm{n}=12)\end{array}$ & $\begin{array}{l}\text { ADA (Uveitis) } \\
\quad(n=13)\end{array}$ & $\underset{(n=49)}{\text { ETA }}$ & $\begin{array}{c}P \text { between } \\
\text { ADA (no } \\
\text { Uveitis) and } \\
\text { ADA (Uveitis) }\end{array}$ & $\begin{array}{l}P \text { between } \\
\text { ADA (no } \\
\text { Uveitis) and } \\
\text { ETA (no } \\
\text { Uveitis) } \\
\end{array}$ & $\begin{array}{c}P \text { between } \\
\text { ADA (Uveitis) } \\
\text { and ETA (no } \\
\text { Uveitis) }\end{array}$ \\
\hline Females, n (\%) & $6(50 \%)$ & $8(61.54 \%)$ & $41(83.67 \%)$ & 0.859 & 0.035 & 0.174 \\
\hline $\begin{array}{l}\text { Active uveitis at the start of treatment, } \mathrm{n} \\
(\%)\end{array}$ & $0(0 \%)$ & $13(100 \%)$ & $0(0 \%)$ & $<0.001$ & - & $<0.001$ \\
\hline Diagnosis & - & - & - & - & - & - \\
\hline extended oligoarthritis, n (\%) & $0(0 \%)$ & $2(15.38 \%)$ & $7(14.29 \%)$ & \multirow{4}{*}{0.706} & \multirow{4}{*}{0.011} & \multirow{4}{*}{0.225} \\
\hline persistent oligoarthritis, n (\%) & $5(41.67 \%)$ & $6(46.15 \%)$ & $32(65.31 \%)$ & & & \\
\hline RF- polyarthritis, $\mathrm{n}(\%)$ & $5(41.67 \%)$ & $4(30.77 \%)$ & $10(20.41 \%)$ & & & \\
\hline psoriatic arthritis, n (\%) & $2(16.67 \%)$ & $1(7.69 \%)$ & $0(0 \%)$ & & & \\
\hline $\begin{array}{c}\text { Age at disease onset, median (IQR), } \\
\text { years }\end{array}$ & $2.25(1.38: 3.08)$ & $2(1.5: 2.9)$ & $1.8(1.4: 2.2)$ & 0,7 & 0,283 & 0.258 \\
\hline $\begin{array}{c}\text { Age at start of current therapy } \\
\text { (ETA/ADA), median (IQR), years }\end{array}$ & $3.9(3.1: 4)$ & $3.7(3.4: 3.9)$ & $2.8(2: 3)$ & 0.56 & $<0.001$ & 0.003 \\
\hline $\begin{array}{c}\text { JIA duration before start ETA/ADA, } \\
\text { median } \\
\text { (IQR), years }\end{array}$ & $1(0.57: 1.7)$ & $1.1(0.9: 2)$ & $0.6(0.4: 1)$ & 0.682 & 0.054 & 0.012 \\
\hline Prior therapy with biologics, $\mathrm{n}(\%)$ & $4(33.3 \%)$ & $4(30.8 \%)$ & $2(4.1 \%)$ & $>0.999$ & 0.011 & 0.015 \\
\hline Prior therapy with methotrexate, $\mathrm{n}(\%)$ & $11(91.7 \%)$ & $13(100 \%)$ & $31(63.3 \%)$ & $>0.999$ & 0.083 & 0.013 \\
\hline
\end{tabular}

ETA - Etanercept, ADA - adalimumab, IQR - interquartile range.

depending on the type of the data being analyzed.

All the reported $p$-values were based on two-tailed tests of significance; the $p$-values $<0.05$ were regarded as statistically significant. The STATISTICA 7.0 software (StatSoft, USA) and RStudio software version 1.0.136 (Free Software Foundation, Inc., USA) with R packages version 3.3.1 (R Foundation for Statistical Computing, Austria) were used for analysis.

\section{RESULTS}

Among 198 patients treated with ETA, 49 patients (41 females, $83.7 \%$ ) younger than 4 years (median age 2.8; IQR $2: 3$ ) without a history of uveitis were enrolled in the study. Among 215 patients treated with ADA, 25 patients (14 females, 56\%) younger than 4 years (median age 3.9; IQR 3.1:4) were enrolled in the study. Patients treated with ADA were subdivided into two subgroups depending on their medical history and the uveitis status. The group of patients with active uveitis consisted of 13 children (8 females, $61.5 \%$ ); the group of patients without active uveitis involved 12 children ( 6 females, 50\%). Table 1 summarizes the demographic characteristics for the three groups. Patients treated with ETA and ADA differed in terms of JIA categories: there were no patients with psoriatic arthritis in the group treated with ETA, while the group treated with ADA included three $(3 / 25,12 \%)$ patients with psoriatic arthritis. Furthermore, there were no children with extended oligoarthritis in the group of patients without a history of uveitis who were treated with ADA, while the percentage of these children in two other groups was approximately $15 \%$. The number of children younger than 3 years was much greater in the ETA group, so this group differed from the ADA groups in terms of JIA duration and age.
The median disease duration before treatment beginning was $1(0.57: 1.7)$ year in the group of ADA patients without uveitis; $1.1(0.9: 2)$ years in the group of ADA patients with uveitis; and $0.6(0.4: 1)$ years in ETA patients. The median age at start of treatment was $3.9(3.1: 4)$ years in the group of ADA patients without uveitis; 3.7 (3.4: 3.9) years in the group of ADA patients with uveitis; and 2.8 (2: 3) years in ETA patients. A total of 6 patients received Glucocorticosteroids (GC) before initiation of treatment with biologics (3 subjects in the group of ADA patients with uveitis, 1 subject in the group of ADA patients without uveitis, and 2 subjects in the ETA group), and only 1 patient received GC as background therapy at initiation of ADA treatment. Four patients in each ADA group $(33.3 \%$ and $30.8 \%$ in groups without and with uveitis, respectively) were previously treated with biologics and only two patients (4.1\%) in the ETA group previously received antiTNF therapy.

The data on arthritis severity and arthritis activity at baseline are summarized in Table 2. All patients had active arthritis; ADA patients without uveitis had a higher CHAQ score for disease activity compared to ADA patients with uveitis $(p=0.036)$.

\subsection{Efficacy Analysis}

Treatment with ADA and ETA in children younger than 4 years proved highly efficacious already after the first month. A statistically significant reduction of the CHAQ and JADAS scores for disease activity, laboratory values (the CRP level and ESR), duration of morning stiffness, and the VAS score (assessed by the physician and the patient) after 4-week therapy was observed in all three groups $(p<0.01)$. Significant reduction in the number of affected joints (swollen or painful joints, joints with the limited range of motion and with active arthritis) was achieved after 3 months of treatment in all three 
groups $(p<0.01)$.

The percentage of patients who achieved ACR50/70/90 after 6-month therapy was $89.8 / 87.8 / 73.5 \%$, respectively, in the ETA group; $92.3 \% / 92.3 \% / 69.2 \%$ in the ADA group with uveitis; and 75-/41.7/41.7\% in the ADA group without uveitis.

The percentage of patients who achieved ACR50/ 70/90 after 12 -month therapy was $87.8 / 85.7 / 77.6 \%$ in the ETA group; 92.3/92.3/84.6\% in the ADA group with uveitis; and $75 / 58.3 / 41.7 \%$ in the ADA group without uveitis. The percentage of patients who achieved ACR50/70/90 by the end of the follow-up period, with allowance for patients who discontinued treatment because of AEs or poor efficacy, was $85.7 / 83.7 / 77.6 \%$, respectively, in the ETA group; $76.9 / 76.9 / 69.2 \%$ in the ADA group with uveitis; and 75$158.3 / 41.7 \%$ in the ADA group without uveitis. Hence, the groups differed in the dynamics of achieving the ACR criteria (Figs. 1 and 2). Comparable efficacy was shown for ADA patients with uveitis and ETA patients without uveitis, while a significantly lower percentage of children reached ACR70/90 in the ADA group without uveitis.

Table 2. The parameters of disease severity in groups at baseline.

\begin{tabular}{|c|c|c|c|c|c|c|}
\hline- & $\begin{array}{l}\text { ADA (no Uveitis) } \\
\qquad(\mathrm{n}=12)\end{array}$ & $\begin{array}{l}\text { ADA (Uveitis) } \\
\qquad(\mathbf{n}=13)\end{array}$ & $\begin{array}{c}\text { ETA (no Uveitis) } \\
(n=49)\end{array}$ & $\begin{array}{c}p \text { between ADA } \\
\text { (no Uveitis) and } \\
\text { ADA (Uveitis) }\end{array}$ & $\begin{array}{c}p \text { between ADA } \\
\text { (no Uveitis) and } \\
\text { ETA (no } \\
\text { Uveitis) } \\
\end{array}$ & $\begin{array}{c}p \text { between ADA } \\
\text { (Uveitis) and } \\
\text { ETA (no } \\
\text { Uveitis) }\end{array}$ \\
\hline $\begin{array}{l}\text { Erythrocyte sedimentation } \\
\text { rate, } \mathrm{mm} / \mathrm{h}\end{array}$ & $22.5(13: 47.25)$ & $29(12: 37)$ & $20(15: 29)$ & 0.604 & 0.723 & 0.808 \\
\hline C-reactive protein, $\mathrm{mg} / \mathrm{l}$ & $20.17(2.01: 31.7)$ & $6.85(1: 9)$ & $5.42(1.17: 19.14)$ & 0.299 & 0.197 & 0.735 \\
\hline Morning stiffness, min & $60(30: 195)$ & $60(20: 120)$ & $60(0: 86.25)$ & 0.721 & 0.328 & 0.474 \\
\hline Painful joint count & $5.5(2: 16.5)$ & $3(2: 5)$ & $2(2: 5)$ & 0.236 & 0.168 & 0.951 \\
\hline Swollen joint count & $4(2: 15.75)$ & $3(2: 5)$ & $3(2: 6)$ & 0.308 & 0.637 & 0.439 \\
\hline Limited joint count & $5.5(2: 16.5)$ & $4(2: 5)$ & $3(2: 5)$ & 0.426 & 0.361 & 0.881 \\
\hline Active joint count & $5.5(2: 16.5)$ & $3(2: 5)$ & $3(2: 5)$ & 0.236 & 0.384 & 0.515 \\
\hline patVAS & $81.5(56.75: 88.5)$ & $58(50: 64)$ & $58(45: 80)$ & 0.057 & 0.073 & 0.555 \\
\hline phyVAS & 89.5 (69.25: 95) & $70(64: 86)$ & $70(58: 90)$ & 0.134 & 0.106 & 0.897 \\
\hline CHAQ & $2(0.88: 2.5)$ & $0.88(0.5: 1.25)$ & $1(0.7: 1.88)$ & 0.036 & 0.055 & 0.224 \\
\hline JADAS71 & $22.25(18.45: 35.1)$ & $17(13.2: 20.6)$ & $18.1(13.6: 21.3)$ & 0.068 & 0.056 & 0.697 \\
\hline
\end{tabular}

Groups: $+\mathrm{ADA}$ (no uveitis) + ADA(uveitis) +• ETA(no uveitis)

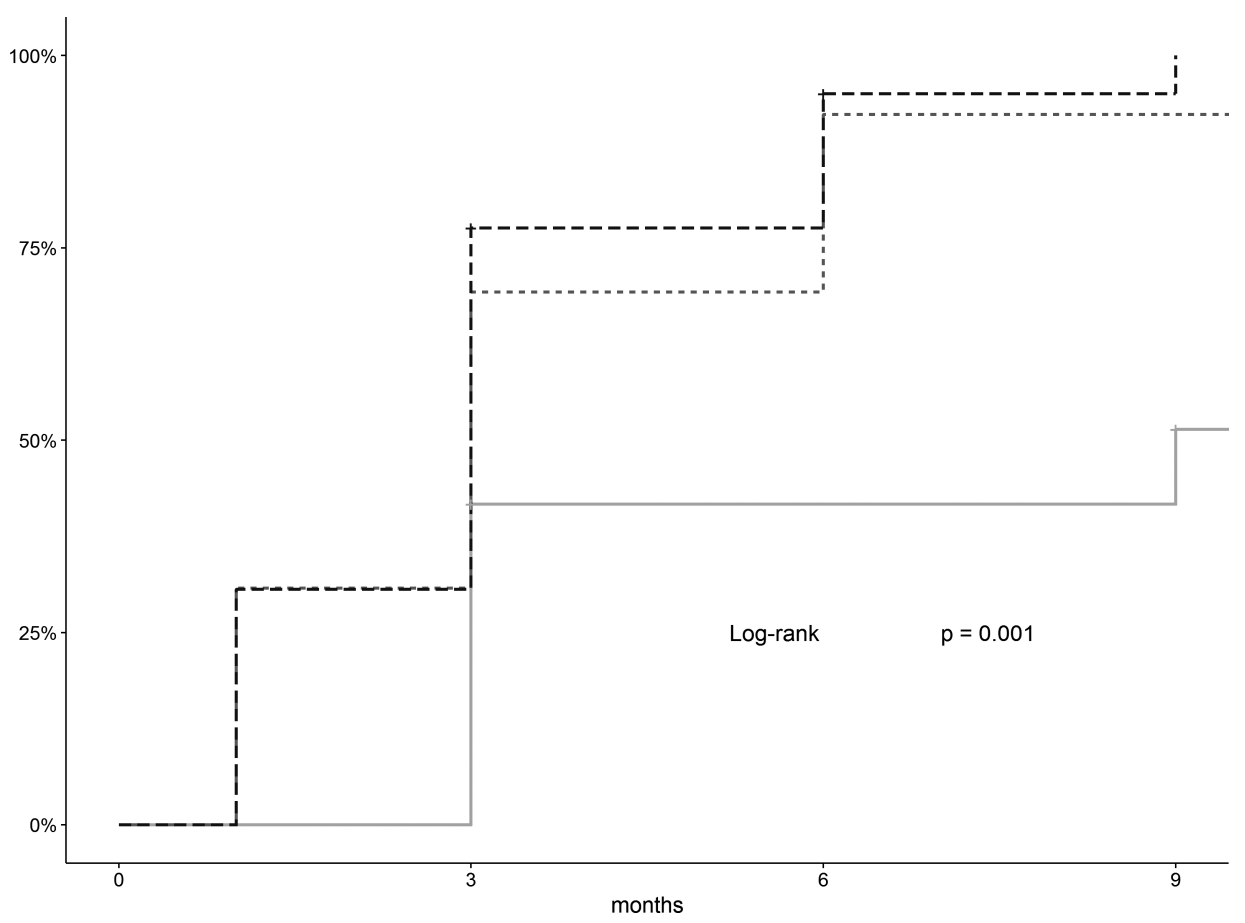

Fig. (1). The dynamics of achieving ACR70 in study groups. 
Groups: + $\mathrm{ADA}$ (no uveitis) + ADA(uveitis) +- ETA(no uveitis)

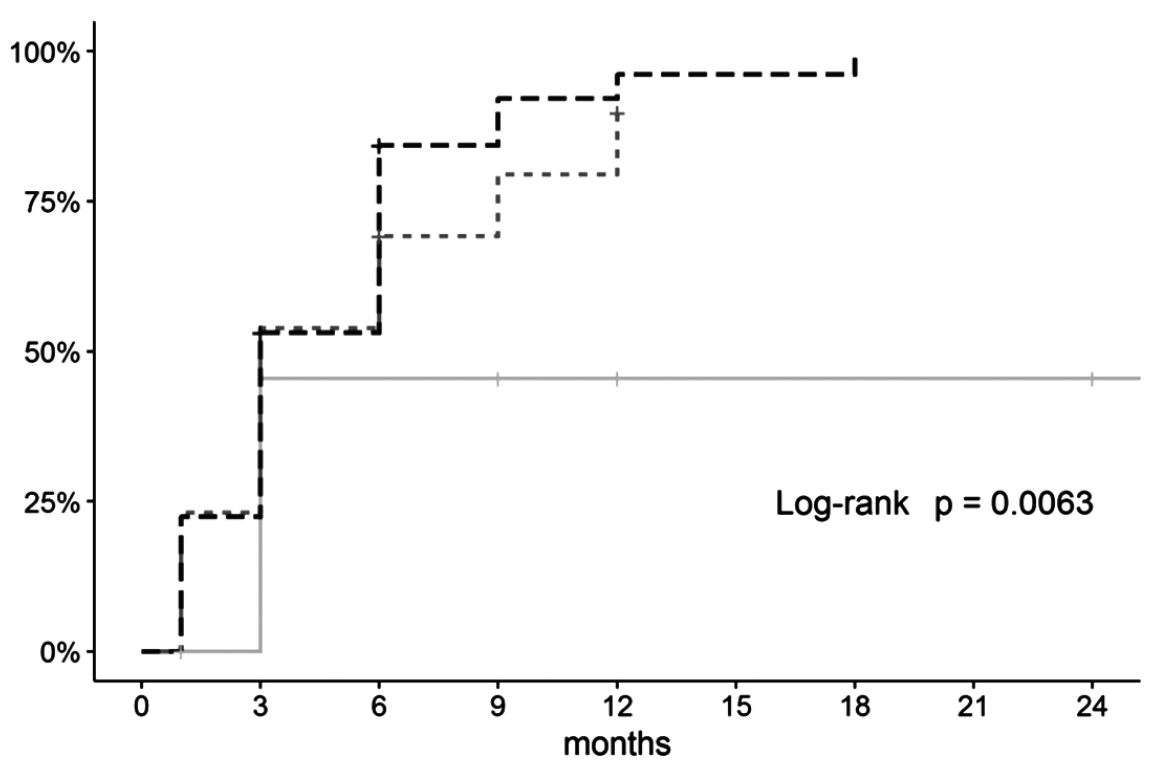

Fig. (2). The dynamics of achieving ACR90 in study groups.

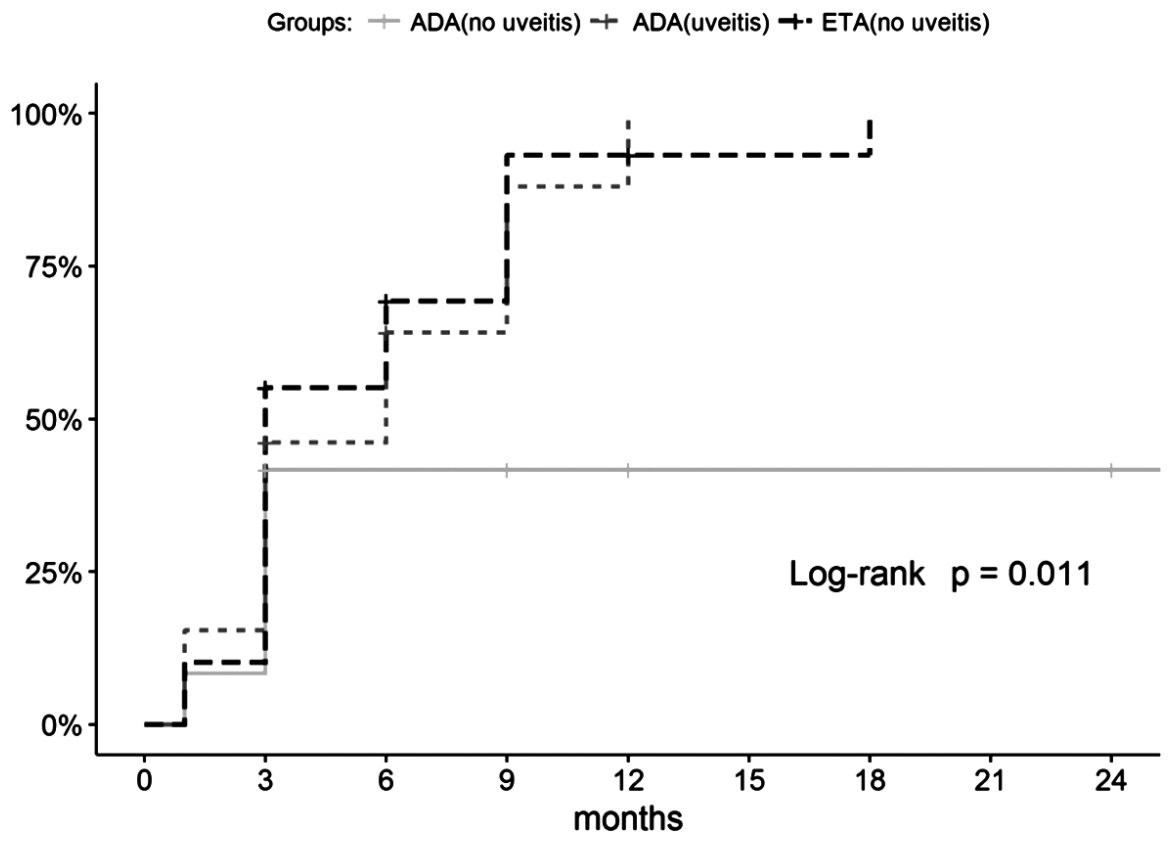

Fig. (3). The dynamics of achieving the Wallace's criteria for inactive disease in study groups.

In the ADA group with uveitis, $11(84.6 \%)$ patients achieved inactive disease after one-month therapy and 12 (92.3\%) patients, after 9-month therapy.

The groups differed in terms of treatment efficacy parameters. The percentages of patients who achieved remission in the ETA group and ADA group with uveitis were comparable (53.1\% and $53.8 \%$, respectively), while only 3 (25\%) patients in the ADA group without uveitis achieved long-term clinical remission ( $p$-values are insignificant: 0.111 compared to ADA group with uveitis and 0.226 compared to ETA group). Furthermore, lower efficacy was observed for the ADA group without uveitis in terms of achieving the inactive disease according to the Wallace ( $p$-value is significant, (Fig. 3) and JADAS71 ( $p$-value is insignificant, Table 3) criteria.

The highest frequency of treatment discontinuation because of adverse events $(n=6,12.2 \%)$ was observed in the ETA group. In two of these six patients $(33 \%)$, the drug was discontinued because of de novo uveitis. No cases of de novo uveitis or uveitis flare were recorded in ADA groups. In the ADA group without uveitis, the frequency of treatment discontinuation because of poor efficacy was somewhat higher ( $p=0.096$ ) compared to that in the ETA group. 
Table 3. The efficacy parameters in groups at the end of follow-up.

\begin{tabular}{|c|c|c|c|c|c|c|}
\hline- & $\begin{array}{c}\text { ADA } \\
\text { (no Uveitis) } \\
(\mathbf{n}=12)\end{array}$ & $\begin{array}{l}\text { ADA (Uveitis) } \\
\quad(\mathbf{n}=13)\end{array}$ & $\begin{array}{c}\text { ETA (no Uveitis) } \\
(\mathrm{n}=49)\end{array}$ & $\begin{array}{c}p \text { between } \\
\text { ADA (no } \\
\text { Uveitis) and } \\
\text { ADA (Uveitis) }\end{array}$ & $\begin{array}{l}p \text { between } \\
\text { ADA (no } \\
\text { Uveitis) and } \\
\text { ETA (no } \\
\text { Uveitis) }\end{array}$ & \begin{tabular}{|}
$p$ between ADA \\
(Uveitis) and \\
ETA (no \\
Uveitis)
\end{tabular} \\
\hline Remission, $\mathrm{n}(\%)$ & $3(25 \%)$ & $7(53.8 \%)$ & $26(53.1 \%)$ & 0.226 & 0.111 & $>0.999$ \\
\hline Inactive disease Wallace, $\mathrm{n}(\%)$ & $4(33.3 \%)$ & $9(69.2 \%)$ & $36(73.5 \%)$ & 0.115 & 0.015 & 0.739 \\
\hline $\begin{array}{c}\text { Inactive disease JADAS71 cut-off } \\
\text { point, } n(\%)\end{array}$ & $4(33.3 \%)$ & $8(61.5 \%)$ & $26(53.1 \%)$ & 0.238 & 0.335 & 0.756 \\
\hline $\begin{array}{c}\text { Treatment discontinuation (adverse } \\
\text { events), } \mathrm{n}(\%)\end{array}$ & $1(8.3 \%)$ & $1(7.7 \%)$ & $6(12.2 \%)$ & $>0.999$ & $>0.999$ & $>0.999$ \\
\hline $\begin{array}{c}\text { Treatment discontinuation (low } \\
\text { efficacy), } \mathrm{n}(\%)\end{array}$ & $2(16.7 \%)$ & $1(7.7 \%)$ & $1(2 \%)$ & 0.593 & 0.096 & 0.378 \\
\hline ACR30, n (\%) & $9(75 \%)$ & $10(76.9 \%)$ & $42(85.7 \%)$ & \multirow{4}{*}{0.89} & \multirow{4}{*}{0.83} & \multirow{4}{*}{$>0.999$} \\
\hline ACR50, n (\%) & $9(75 \%)$ & $10(76.9 \%)$ & $42(85.7 \%)$ & & & \\
\hline ACR70, n (\%) & $7(58.3 \%)$ & $10(76.9 \%)$ & $41(83.7 \%)$ & & & \\
\hline ACR90, n (\%) & $5(41.7 \%)$ & $9(69.2 \%)$ & $38(77.6 \%)$ & & & \\
\hline $\begin{array}{c}\text { Median time to achieve remission, } \\
\text { months, Me (IQR) }\end{array}$ & $9(9: 9)$ & $9(9: 18)$ & $9(9: 12)$ & 0.647 & 0.918 & $>0.999$ \\
\hline
\end{tabular}

Table 4. Safety of ADA/ETA treatment in groups.

\begin{tabular}{|c|c|c|c|}
\hline Type of Adverse Events & $\begin{array}{l}\text { ADA Patients without Uveitis } \\
\text { (n=12, 14.5 Patient-Years) }\end{array}$ & $\begin{array}{c}\text { ADA Patients with Uveitis ( } n=13, \\
27.75 \text { Patient-Years) }\end{array}$ & $\begin{array}{c}\text { ETA Patients }(\mathrm{n}=49,75.25 \\
\text { Patient-Years) }\end{array}$ \\
\hline Infectious AEs, rate & 13.8 per 100 patient-years & 51.4 per 100 patient-years & 39.9 per 100 patient-years \\
\hline Acute respiratory virus infection & 0 & 11 & 25 \\
\hline \begin{tabular}{|l|} 
Acute bronchitis \\
\end{tabular} & 0 & 1 & 1 \\
\hline Blepharitis & 1 & 0 & 0 \\
\hline Streptococcal pyoderma & 1 & 0 & 0 \\
\hline Rotavirus-induced diarrhea & 0 & 1 & 0 \\
\hline Urinary tract infections & 0 & 1 & 0 \\
\hline Herpes zoster & 0 & 0 & 1 \\
\hline Sinusitis & 0 & 0 & 1 \\
\hline Non-infectious AEs, rate & 34.5 per 100 patient-years & 7.3 per 100 patient-years & 6.6 per 100 patient-years \\
\hline Femoral fracture & $3 *$ & 0 & 0 \\
\hline Nasal hemorrhage & 1 & 0 & 0 \\
\hline Thrombocytopenia & 1 & 0 & 0 \\
\hline Injection site pain & 0 & 1 & 0 \\
\hline Hemorrhagic rash & 0 & 1 & 0 \\
\hline Allergic reaction & 0 & 0 & 1 \\
\hline Elevated transaminase level & 0 & 0 & 2 \\
\hline Neutropenia & 0 & 0 & 2 \\
\hline
\end{tabular}

* only one case was classified as possibly related to the ADA+MTX treatment.

\subsection{Safety Analysis}

A total of 23 adverse events developed in $16(64 \%)$ ADA patients over the follow-up period (41.75 patient-years); the frequency of AEs was 55.1 AEs per 100 patient-years. Thirtythree AEs developed in $14(28.6 \%)$ ETA patients $(75.25$ patient-years); the frequency of AEs was 43.9 per 100 patientyears. The general frequency of infectious adverse events in the ADA group was comparable to that in the ETA group, while the frequency of non-infectious AEs was higher (Table 4). However, the frequency of infectious AEs differed significantly depending on the uveitis status in the ADA group. Only two infectious complications (13.8 per 100 patient-years) were reported in ADA patients without uveitis, while ADA patients with uveitis (27.25 patient-years) had 14 infectious complications (51.4 per 100 patient-years), which was significantly higher compared to that in the ADA group without uveitis (13.8 per 100 patient-years) and in the ETA group (39.9 per 100 patient-years). The highest frequency of non-infectious complications (34.5 per 100 patient-years) was observed in the ADA group without uveitis ( 3 patients, 5 AEs) as compared to 7.3 per 100 patient-years in the ADA group with uveitis and 6.6 per 100 patient-years in the ETA group. Bone complications (femoral fractures in 3 patients) were reported only for the ADA group without uveitis. Out of these 3 cases, only 
one was classified as possibly related to the received treatment (MTX + ADA combination) and treatment was discontinued because of poor efficacy; the patient had no prior history of therapy with GCs. Two other fractures were traumatic and were classified as not related to ADA treatment.

\section{DISCUSSION}

The results obtained at the National Scientific and Practical Center of Children's Health were used to analyze the data for 74 JIA patients younger than 4 years who were treated with etanercept or adalimumab. In this age group, ETA (for the cohort of patients without uveitis) and ADA (for patients with active uveitis) had a good efficacy and tolerability profile, while administration of ADA in patients younger than 4 years without active uveitis was less efficacious and was associated with a higher risk of AEs. Comparison of the efficacy variables for therapies with two anti-TNF drugs showed that such factor as presence/absence of active uveitis must be taken into account when prescribing ETA and ADA to children younger than 4 years.

Limited data on the application of TNF inhibitors in children with JIA under 4 years of age are currently available. Several studies on the efficacy and safety of ETA or ADA in this population have been conducted.

An attempt to compare the efficacy and safety profiles of ADA and ETA in children with JIA younger than 4 years was made in a single study [5]. Windschall and Horneff demonstrated that although efficacies of these drugs were comparable, the risk of infectious complications was somewhat higher in the ADA group. However, the studied groups significantly differed in their uveitis status at the start of treatment point, which was not taken into account during efficacy and safety analysis. We suggested that the presence of uveitis is one of the predictors of patient's response to treatment with anti-TNF drugs. Since prescription of ETA to children with uveitis may be associated with the increased risk of uveitis flare [2, 14], ADA is the drug of choice for children with a history of uveitis in older age groups. However, no algorithm for selecting the optimal anti-TNF drug in children of younger age that would take into account the presence or absence of active uveitis is currently available. We have demonstrated in this study that the presence of active uveitis must be taken into account when selecting anti-TNF treatment for children aged $<$ 4 years. ETA is the drug of choice in patients without active uveitis: it shows high efficacy upon achieving ACR. However, it is characterized by poor efficacy against uveitis (the observed frequency of de novo uveitis ranges from $4 \%$ according to our data to $10 \%$ according to the large-scale cohort studies); the frequency of infectious AEs is higher compared to that of ADA in non-uveitis patients (39.9 vs 13.8 per 100 patient-years). ADA is the drug of choice in children with active uveitis: it shows comparable efficacy in terms of achieving ACR with no uveitis flares and no cases of de novo uveitis. Furthermore, prescription of ADA to children younger than 4 years is associated with the risk of bone complications (in 3 children out of 12; 20.7 per 100 patient-years).

Hence, we have confirmed in this study that the efficacies of ADA and ETA differ in children with JIA aged $<4$ years depending on the presence of active uveitis.

Comparison of the ACR90 response rates between the children with active uveitis and without uveitis showed that different rates of favorable clinical responses were observed in both groups. Namely, ACR90 was achieved in $53.8 \%$ of patients with uveitis and $27 \%$ of patients without uveitis after oneyear treatment. In the ETA group without active uveitis, ACR90 was achieved in $76 \%$ of patients after one-year treatment. The published studies show significant heterogeneity in efficacy variables. Windschall and Horneff (2016) [5] reported that a very small percentage of patients $(22 \%$ of 11 patients) achieved ACR90 over a long-term follow-up period; $45 \%$ of patients had active uveitis at baseline. Kingsbury et al. (2013) [7] reported that $62 \%$ out of 32 patients achieved ACR90 but did not mention what percentage of patients had active uveitis. The efficacy of achieving ACR90 response in the overall cohort of patients treated with ADA in our study ranked intermediate between these two studies. The difference can be seen for the groups without uveitis and with uveitis $(41.7 \%$ vs $69.2 \%)$. The differences in efficacy revealed in the published literature can possibly be related, among other factors, to the percentage of patients with active uveitis at baseline.

The data on the achievement of clinical remission was reported only in one article [5]: $66 \%$ of patients according to the JADAS criteria after 2year therapy. According to our findings, the comparable percentages of patients in groups treated with ETA and ADA (with uveitis) achieved remission according to both the Wallace and JADAS criteria, but fewer patients without uveitis treated with ADA achieved sustained remission. However, it should be mentioned that in the latter group, patients' condition at baseline was more severe compared to that in two other groups. Nevertheless, at least $75 \%$ of patients achieved the lower threshold of response to therapy (ACR30) in all study groups. Interestingly, the efficacy reported by Windschall and Horneff (2016) for the ETA group was somewhat lower (the difference did not reach statistical significance), while an opposite trend was observed in our study. This difference can be attributed to the fact that our sample of ETA patients included significantly more children with oligoarthritis as compared to the cohort of patients treated with ADA; in addition, disease activity in our sample was lower according to some baseline parameters.

A $50 \%$ flare rate was reported for patients who discontinued treatment with TNF inhibitors due to remission [5]. In our study, none of ADA or ETA patients discontinued treatment after sustained remission had been achieved because of the high risk of flare.

Our study has a number of limitations. The groups being compared differed significantly at baseline in parameters such as distribution by JIA categories, disease duration, and the CHAQ score for disease activity. Nevertheless, we have accumulated a significant body of real-world data, which represent the situation in clinical practice using the local data and can be compared to the results for patients from other countries. The existing intergroup differences did not allow us to retrospectively select the groups being compared without significant loss in sample size. 


\section{CONCLUSION}

Our results demonstrate that ETA and ADA have advantages in terms of their efficacy for different patient groups according to baseline clinical parameters in patients younger than 4 years. ADA is preferred for achieving ACR70/90 and inactive stage of the disease according to the Wallace criteria in patients with uveitis compared to those without uveitis. Children without uveitis show a better response to ETA but require careful monitoring by ophthalmologists as the efficacy of this drug against uveitis is low. Hence, ADA is the drug of choice for children with uveitis aged $<4$ years, while ETA is preferred in children without uveitis.

\section{ETHICAL APPROVAL AND CONSENT TO PART- ICIPATE}

The study was approved by the Local Ethics Committee of the National Medical Research Center of Children's Health (Protocol no. 36, dated October 16, 2008).

\section{HUMAN AND ANIMAL RIGHTS}

No Animals were used in this research. All human research procedures followed were in accordance with the ethical standards of the committee responsible for human experimentation (institutional and national), and with the Helsinki Declaration of 1975, as revised in 2013.

\section{CONSENT FOR PUBLICATION}

Informed consent was taken from the patients when they were enrolled.

\section{CONFLICT OF INTEREST}

The authors declare no conflict of interest, financial or otherwise.

\section{ACKNOWLEDGEMENTS}

This study would not have been possible without the collaboration of numerous Russian pediatric rheumatologists, patients, and patients' parents.

\section{REFERENCES}

[1] Schmeling H, Minden K, Foeldvari I, Ganser G, Hospach T, Horneff G. Efficacy and safety of adalimumab as the first and second biologic agent in juvenile idiopathic arthritis: The german biologics JIA registry. Arthritis Rheumatol 2014; 66(9): 2580-9. [http://dx.doi.org/10.1002/art.38741] [PMID: 24942886]

[2] Klotsche J, Niewerth M, Haas JP, et al. Long-term safety of etanercept and adalimumab compared to methotrexate in patients with Juvenile
Idiopathic Arthritis (JIA). Ann Rheum Dis 2016; 75(5): 855-61. [http://dx.doi.org/10.1136/annrheumdis-annrheumdis-2014-206747] [PMID: 25926155]

[3] Zannin ME, Birolo C, Gerloni VM, et al. Safety and efficacy of infliximab and adalimumab for refractory uveitis in juvenile idiopathic arthritis: 1-year followup data from the italian registry. J Rheumatol 2013; 40(1): 74-9

[http://dx.doi.org/10.3899/jrheum.120583] [PMID: 23118110]

[4] Otten MH, Anink J, Prince FHM, et al. Trends in prescription of biological agents and outcomes of juvenile idiopathic arthritis: Results of the Dutch national arthritis and biologics in children register. Ann Rheum Dis 2015; 74(7): 1379-86.

[http://dx.doi.org/10.1136/annrheumdis-2013-204641] [PMID: 246419 40]

[5] Windschall D, Horneff G. Safety and efficacy of etanercept and adalimumab in children aged 2 to 4 years with juvenile idiopathic arthritis. Clin Rheumatol 2016; 35(12): 2925-31.

[http://dx.doi.org/10.1007/s10067-016-3439-y] [PMID: 27709443]

[6] La Torre F, Cattalini M, Teruzzi B, Meini A, Moramarco F, Iannone F. Efficacy of adalimumab in young children with juvenile idiopathic arthritis and chronic uveitis: A case series. BMC Res Notes 2014; 7(1): 316.

[http://dx.doi.org/10.1186/1756-0500-7-316] [PMID: 24886032]

[7] Kingsbury DJ, Bader-Meunier B, Patel G, Arora V, Kalabic J, Kupper H. Safety, effectiveness, and pharmacokinetics of adalimumab in children with polyarticular juvenile idiopathic arthritis aged 2 to 4 years. Clin Rheumatol 2014; 33(10): 1433-41.

[http://dx.doi.org/10.1007/s10067-014-2498-1] [PMID: 24487484]

[8] Bracaglia C, Buonuomo PS, Tozzi AE, et al. Safety and efficacy of etanercept in a cohort of patients with juvenile idiopathic arthritis under 4 years of age. J Rheumatol 2012; 39(6): 1287-90.

[http://dx.doi.org/10.3899/jrheum.111555] [PMID: 22589254]

[9] Alexeeva EI, Namazova-Baranova LS, Bzarova TM, Valieva SI, Denisova R V, Sleptsova T V, et al. Predictors of the response to etanercept in patients with juvenile idiopathic arthritis without systemic manifestations within 12 months: Results of an open-label, prospective study conducted at the National Scientific and Practical Center of Children's. H Pediatr Rheumatol 2017; 15(1)

[10] McErlane F, Beresford MW, Baildam EM, et al. Validity of a threevariable Juvenile Arthritis disease activity score in children with newonset juvenile idiopathic arthritis. Ann Rheum Dis 2013; 72(12): 1983-8.

[http://dx.doi.org/10.1136/annrheumdis-2012-202031] [PMID: 232569 51]

[11] Ruperto N, Ravelli A, Pistorio A, et al. Psychometric evaluation of the Childhood Health Assessment Questionnaire (CHAQ) and the Child Health Questionnaire (CHQ) in 32 countries. Review of the general methodology. Clin Exp Rheumatol 2001; 19(4)(Suppl. 23): S1-9. [PMID: 11510308]

[12] Giannini EH, Ilowite NT, Lovell DJ, et al. Long-term safety and effectiveness of etanercept in children with selected categories of juvenile idiopathic arthritis. Arthritis Rheum 2009; 60(9): 2794-804. [http://dx.doi.org/10.1002/art.24777] [PMID: 19714630]

[13] Wallace CA, Giannini EH, Huang B, Itert L, Ruperto N. American College of Rheumatology provisional criteria for defining clinical inactive disease in select categories of juvenile idiopathic arthritis. Arthritis Care Res (Hoboken) 2011; 63(7): 929-36. [http://dx.doi.org/10.1002/acr.20497] [PMID: 21717596]

[14] Verazza S, Davì S, Consolaro A, et al. Disease status, reasons for discontinuation and adverse events in 1038 Italian children with juvenile idiopathic arthritis treated with etanercept. Pediatr Rheumatol Online J 2016; 14(1): 68 .

[http://dx.doi.org/10.1186/s12969-016-0126-0] [PMID: 27993144]

(C) 2019 Alexeeva et al.

This is an open access article distributed under the terms of the Creative Commons Attribution 4.0 International Public License (CC-BY 4.0), a copy of which is available at: (https://creativecommons.org/licenses/by/4.0/legalcode). This license permits unrestricted use, distribution, and reproduction in any medium, provided the original author and source are credited. 